\title{
Comparative Extraction of Pectic and Polyphenols from Mexican Lime Pomace and Bagasse
}

\author{
${ }^{1}$ Daniela Sanchez-Aldana, ${ }^{2}$ Cristobal Noe Aguilar, \\ ${ }^{2}$ Guadalupe Virginia Nevarez-Moorillon and ${ }^{1}$ Juan Carlos Contreras Esquivel \\ ${ }^{1}$ Department of Food Research, School of Chemistry, \\ Universidad Autónoma de Coahuila Saltillo 25280, Coahuila, Mexico \\ ${ }^{2}$ Laboratory of Food Microbiology, Facultad de Ciencias Químicas, \\ Universidad Autónoma de Chihuahua Chihuahua 31125, Chihuahua, Mexico
}

Received 2013-10-05, Revised 2013-10-25; Accepted 2013-10-29

\begin{abstract}
Mexican lime bagasse and pomace are rich in pectin and they also represent an important source of valueadded compounds such as polyphenols. Two different options for the combined recovery of pectin and phenolic compounds from Mexican lime bagasse and pomace, two byproducts of industrial lime processing, were developed. Conventional and microwave-assisted extraction methods were used. All pectic extracts presented a degree of esterification in the range of $70 \%$. Pomace extracts had the higher pectin yield and the lower polyphenol content. Among the bioactive compounds identified by HPLC were two flavonones, naringin and hesperidin, all compounds were present in low concentration in the pectic extracts. Microwave pectic extracts presented depolymerization, as observed by molecular weight determination (12 KDa) and compared against conventional pectic extracts which presented a molecular weight of $670 \mathrm{KDa}$. The film forming capacity of pectic extracts was also evaluated. Antioxidant activity of pectic extracts was also assessed by three different methods; all extracts showed a better activity in $\mathrm{Fe}^{2+}$ chelating assay (62.85$73.32 \%$ ) and lipid oxidation inhibition (63.07-72.28\%) than in DPPH radical inhibition (5.32-6.65\%). These findings indicate a correlation between the amount of phenolic compounds and the antioxidative capacity. Conventional pectic extracts from Mexican lime bagasse and pomace presented bioactive compounds with potential application for edible films and coatings in food industry.
\end{abstract}

Keywords: Pectin, Conventional Extraction, Microwave Extraction, Mexican Lime

\section{INTRODUCTION}

Citric fruits are consumed worldwide. In Mexico, they are one of the most important industrial crops and they account for $40 \%$ of the fruit-related cultivable surface, mainly in the Mexican South Pacific Coast, from Colima to Oaxaca. Mexican lime (Citrus aurantifolia Swingle) has an enormous economic potential, since Mexico produces $22 \%$ of fruit production worldwide (Recent reports of the Mexican Association for Agricultural Development). This fruit is used mainly in the beverage industry and for essential oil extraction. However, a considerable quantity of waste from bagasse is generated during citrus juice processing, closely to $45 \%$ of the fruit total weight (Ahmad et al., 2006; Ma et al., 2009). Although these wastes are used as animal feed and biofuel, the majority is discarded, causing environmental pollution. Therefore, citrus processing industries have been searching for applications for these wastes which are a rich source of natural chemical components, including phenolic compounds (mainly flavonoids) and other nutrients (vitamins, minerals, dietary fiber, essential oils, carotenoids and pectin) (Li et al., 2006; Masmoudi et al., 2008; Gonzalez-Molina et al., 2010).

Pectin is a complex vegetal polysaccharide found in the intercellular regions of the primary cell wall of

\footnotetext{
Corresponding Author: Juan Carlos Contreras Esquivel, Department of Food Research, School of Chemistry, Universidad Autónoma de Coahuila Saltillo 25280, Coahuila, Mexico Tel: 52(844)4161238
} 
fruits and vegetables (Sothornvit and Pitak, 2007). Pectin is heterogeneous, with hygroscopic properties, is acid and water soluble, it does have gelling properties and can be used as a stabilizer of emulsions; because of those characteristics, it is considered a polymer with applications in pharmaceutical and food industries (Zapata et al., 2009; Coma, 2010). Recently, there have been some investigations into the use of pectin as raw material for preparation of edible films and coatings as an alternative to non-biodegradable packaging, that are considered environmental pollutants (Shrestha et al., 2003; Fishman et al., 2004; Maftoonazad et al., 2007; Assifaoui et al., 2010; Coma, 2010). Pectin is extracted from by-products or wastes from the fruit juice industry, mainly from apple pomace and citrus bagasse (Bochek et al., 2001). The main property of pectin is the ability to form gels; in fact, pectin gelling properties depend on several factors (uronic acids content, $\mathrm{pH}$, degree of esterification, presence of solutes, molecular size). The degree of esterification is a critical parameter that influences the ability of pectin to form a gel (Coma, 2010). Commercial pectin are extracted conventionally at high temperatures by hydrolyzing protopectin by the use of acids such as sulfuric, phosphoric, nitric, hydrochloric or citric acid. Microbiological and enzymatic extraction methods are also widely used to obtain pectic extracts (Bochek et al., 2001; Sothornvit and Pitak, 2007; Zapata et al., 2009; Coma, 2010). Conventional extraction is the simplest and oldest method for removing the pectic acids from plant tissues, but this procedure has several disadvantages, including longer preparation time and lowered pectin yield than the pectin obtained by other methods (Fishman et al., 2006; Liu et al., 2006; Wang et al., 2007; Yapo et al., 2007; Yeoh et al., 2008) Microwave assisted extraction is a potentially feasible method to obtain pectin and other value-added compounds such polyphenols from agroindustrial wastes (Wang et al., 2007). The main advantages of microwave pectic extraction includes a rapid heating time because of the closed vessel used, control of temperature and pressure, for higher temperatures, higher pressures and insignificant volatility of solvents (Fishman et al., 2006). There are some reports that demonstrate that microwave extraction can lead to a considerable increase in yield and quality of extracted pectin (Bagherian et al., 2011); also, it has been demonstrated that $\mathrm{pH}$, temperature, extraction time, agitation and solid to liquid ratio had effects on pectin yield and quality (Yapo et al., 2007; Bagherian et al., 2011). El-Nawawi and Shehata (1996) studied the effects of conditions on the yield of pectin extracted from Egyptian orange; they found a higher yield at $90^{\circ} \mathrm{C}, \mathrm{pH}$ of 1.7 and $2 \mathrm{~h}$ of extraction. Fishman et al. (2006) used microwave heating to extract pectin under different conditions from lime peel and studied their effect on the yield and characteristics of pectin. In contrast, Liu et al. (2006) studied different extraction techniques using water at different $\mathrm{pH}$ and solvent ratios and found a higher yields with Soxhlet extraction than with Microwave extraction. Masmoudi et al. (2008) used acidified date juice to extract pectin from lemon byproduct and found optimal conditions at $84.3^{\circ} \mathrm{C}, 3 \mathrm{~h} 34$ min of extraction time and $\mathrm{pH} 2.8$. Yeoh et al. (2008) used microwave and conventional methods to obtain pectin from orange peel with different extraction periods, different solvent $\mathrm{pH}$ and different types of solvent systems and found that a fifteen-minute microwave heating period was enough to extract the same amount of pectin as obtained from the traditional three-hour Soxhlet extraction period.

Mexican lime bagasse and pomace have an important potential of industrial relevance, because these are byproducts of the lime processing industry and are excellent sources to extract high amounts of value-added bioactive molecules. These applications can be promising outcomes from an environmental and economic point of view. In our preliminary studies lime residues were found to be a rich source of pectin and phenolic compounds. Therefore, two alternative processes for the combined recovery of pectin and polyphenols, which can easily be integrated in an existing pectin production process, were developed in the present study. Furthermore, these two Mexican Lime raw materials were physicochemically characterized.

\section{MATERIALS AND METHODS}

\subsection{Raw Materials}

Mexican lime (C. aurantifolia Swingle) bagasse and pomace samples were obtained from the States of Chihuahua and Guerrero, Mexico, respectively. Bagasse is the product obtained after juice extraction including seeds, while pomace is the bagasse that was subjected to washing steps and a blanching process. Both materials were dried at $40^{\circ} \mathrm{C}$ and milled with a food processor.

\subsection{Preparation of Pectic Extracts from Lime Bagasse and Pomace}

Four Pectic Extracts (PE) were obtained by two methods for both raw materials.

Conventional method: Dry mass (6 g) of Mexican lime bagasse or pomace was placed in an Erlenmeyer flask with $120 \mathrm{~mL}$ of $1 \%$ citric acid solution. The mixture was stirred during all the extraction at $90^{\circ} \mathrm{C}$ for $1 \mathrm{~h}$. The mixture was then filtered through a cheesecloth funnel.

Microwave assisted method: Pectic extraction was carried out as described by Fishman et al. (2006). Dry mass $(2 \mathrm{~g})$ of bagasse or pomace were placed in a reactor with $60 \mathrm{~mL}$ of $1 \%$ citric acid solution. The mixture was stirred during the extraction at $120^{\circ} \mathrm{C}$ for 5 minutes at 800 watts in a Mars Xpress microwave (CEM, USA); the mixture was then filtered through a cheesecloth funnel. 


\subsection{Proximate Analyses}

Raw materials were characterized by the determination of proteins, carbohydrates, lipids, crude fiber and ash according to methods AOAC, 1998.

\subsection{Physicochemical Characterization of PE}

Uronic acids concentration was determined spectrophotometrically according to the m-hydroxydiphenyl method developed by Blumenkrantz and Asboe-Hansen (1973). The Degree of Esterification (DE) was obtained according to Gee et al. (1959). Total sugars content was determinate spectrophotometrically according to the Dubois et al. (1956) method. Pectin yield was also determined as follows Equation (1):

Yield of pectin $(\%)=\left(\mathrm{m}_{1} / \mathrm{m}\right) \times 100$

where, $\mathrm{m}_{1}(\mathrm{~g})$ is the dried product weight and $\mathrm{m}(\mathrm{g})$ is the dried raw material weight.

\subsection{Polyphenols Extraction}

For polyphenols extraction, bagasse or pomace was suspended in $80 \%$ acetone solution $(1: 4 \mathrm{w} / \mathrm{w})$ and homogenized for $5 \mathrm{~min}$ using a laboratory blender. The slurry was filtered through Whatman No. 1 filter paper in a Buchner funnel. The filter cake was washed twice with the same solution and the filtrate was recovered and analyzed. The recovered filtrates for both bagasse and pomace were evaporated using a rotary evaporator (Büchi Laboratoriums-Technik AG-CH 9230 Flawil, Switzerland) at $40^{\circ} \mathrm{C}$ until less than $10 \%$ of the initial volume remained. The concentrated extracts were recovered with a final volume of $5 \mathrm{~mL}$ of methanol-1\% acetic acid (1:1) and were kept frozen at $-18 \pm 1^{\circ} \mathrm{C}$ until total phenolic content and HPLC analyses were done.

\subsection{Total Phenolic Content}

Total phenolic concentration in PE was determined using the Folin-Ciocalteu colorimetric method, as described by Singleton et al. (1999) with some modifications. As reference for the standard curve, gallic acid was used, with deionized water as solvent. Lime bagasse or pomace extracts $(0.05 \mathrm{~mL})$ were mixed with 3 $\mathrm{mL}$ deionized water and $0.2 \mathrm{~mL}$ Folin-Ciocalteu's phenol reagent (Sigma-Aldrich, USA). After $10 \mathrm{~min}, 0.6$ $\mathrm{mL} 7 \%$ sodium carbonate solution was added and mixed. The mixture was incubated for $30 \mathrm{~min}$ at $37^{\circ} \mathrm{C}$ and then icecooled before absorptions were measured at $755 \mathrm{~nm}$ using a Perkin Elmer spectrophotometer (Lambda 25, USA). Absorbance values were compared with the standard curve to determine the equivalents of Gallic acid (mg Gallic acid equivalents/g dried extract).

\subsection{HPLC Analyses}

HPLC analyses were carried out using a Varian ProStar equipment (Palo Alto, CA, USA). A Varian ProStar 330 Photodiode Array (PDA) detector with detection at $280 \mathrm{~nm}$ was used. Fractionation of the injected material was carried out on a Varian C18 ODS column $(5 \mu \mathrm{m}, 250 \times 4.6 \mathrm{~mm})$ at $30^{\circ} \mathrm{C}, 3 \%$ acetic acid. Total run time was $25 \mathrm{~min}$, equilibrium time $15 \mathrm{~min}$ and pressure ranged from 6 to $400 \mathrm{~atm}$. Flow rate was $1 \mathrm{~mL}$ $\min ^{-1}$ and the injection volume was $10 \mu \mathrm{L}$. Phenolic compounds in the sample were identified by the retention time using the following Sigma standards: hesperidin (USA) and naringin (China). For quantification and identification purposes, external calibration curves were prepared from standards. Other compounds were identified comparing with a database. Solutions were filtered through a $0.45 \mu \mathrm{m}$ membrane filter (Millipore, Bedford, MA, USA) prior to injection. Peak integrated areas obtained from the chromatogram were plotted against known standard concentrations (naringin and hesperidin). Equations generated by linear regression were used to establish the phenolic compound concentrations in the samples.

\subsection{Fourier Transform Infrared (FTIR) Spectroscopy Analyses}

Mexican lime bagasse and pomace PE and commercial citrus pectin (Fagalab, Mexico, 70\% GE) were investigated by Fourier Transformed Infrared Spectroscopy with Attenuated Total Reflectance (FTIR/ATR), which was done in a Perkin Elmer, Spectrum GX (USA) equipment operating at $4 \mathrm{~cm}^{-1}$ resolution. The mirror velocity was $0.08 \mathrm{~cm}^{-1}$ and 50 interferograms were co-added before Fourier transformation. Spectra were collected from 4000 to $650 \mathrm{~cm}^{-1}$.

\subsection{Gel Filtration Chromatography}

The analyses were carried out on a Sephacryl S500 column. Pectic extracts $\left(12 \mathrm{mg} \mathrm{mL} \mathrm{m}^{-1}\right)$ was filtered through $0.7 \mu \mathrm{m}$ celullose microfilters and loaded (500 $\mu \mathrm{L})$ to fractionate on the Fast Performance Liquid Chromatography system (Akta Prime, Amersham Buisciences). Column was equilibrated with $\mathrm{NH}_{4} \mathrm{Cl}$ $0.1 \mathrm{M}$ buffer ( $\mathrm{pH} 4)$ and sample filtered $(180 \mathrm{~mL})$ with with $0.1 \mathrm{M} \mathrm{NH}_{4} \mathrm{Cl}$ buffer, at a flow rate of $1 \mathrm{~mL}$ $\min ^{-1} ; 4 \mathrm{~mL}$ fractions were colected. Void and dead volume were determinated using Dextran blue 2000 and cobalt chloride, respectively. The obtained fractions were analyzed for uronic acids by the colorimetric method described above. 


\subsection{Antioxidant Activity}

The antioxidant activity of PE was tested by three different methods, an oxidation inhibition assay using linoleic acid as the lipid source, a free radical scavenging assay 1,1-Diphenyl-2-Picrylhydrazyl (DPPH) and a $\mathrm{Fe}^{2+}$ chelating assay.

Lipid oxidation inhibition assay: The lipid oxidation inhibition was performed using linoleic acid as the lipid source according to the method described by StarzynskaJaniszewska et al. (2008) with slight modifications. The linoleic acid solution was prepared by adding $0.56 \mathrm{~g}$ of linoleic acid and $1.5 \mathrm{~g}$ of Tween 20 to $8.0 \mathrm{~mL}$ of $96 \%$ ethanol. Each PE $(50 \mu \mathrm{L})$ was mixed with $100 \mu \mathrm{L}$ linoleic acid solution and $1.5 \mathrm{~mL}$ of $0.02 \mathrm{M}$ acetate buffer $(\mathrm{pH}$ 4.0). Controls contained $50 \mu \mathrm{L}$ of distilled water. All samples were mixed in a vortex and emulsions were incubated at $37^{\circ} \mathrm{C}$; after $1 \mathrm{~min}$, Then, $750 \mu \mathrm{L}$ of $50 \mu \mathrm{M}$ $\mathrm{FeCl}_{2}$ solution $\left(0.0994 \mathrm{~g} \mathrm{FeCl}_{2}\right.$ and $0.168 \mathrm{~g}$ EDTA diluted to $1 \mathrm{~L}$ with distilled water) were added to induce the oxidation of linoleic acid. After the chosen incubation times ( 1 and $24 \mathrm{~h}$ ), $1 \mathrm{~mL}$ of $0.1 \mathrm{M} \mathrm{NaOH}$ in $10 \%$ ethanol was added to $250 \mu \mathrm{L}$ of the mixture to stop the oxidation process. After mixing, $2.5 \mathrm{~mL}$ of $10 \%$ ethanol was added and the absorbance measured at $232 \mathrm{~nm}$ against a $10 \%$ ethanol blank. The percentage of antioxidant activity was calculated according to Equation (2):

Inhibition Percentage

$=\left[\left(\mathrm{Abs}_{\text {control }}-\mathrm{Abs}_{\text {sample }}\right) / \mathrm{abs}_{\text {control }}\right] \times 100$

DPPH scavenging capacity assay: The DPPH assay was carried out according to the methodology proposed by Molyneux (2004) $2.90 \mathrm{~mL}$ of $60 \mu \mathrm{M}$ DPPH was added to $100 \mu \mathrm{L}$ of each PE. The samples were placed in the dark and after $30 \mathrm{~min}$ the absorbance (Abs) was determined at $517 \mathrm{~nm}$. Controls contained $100 \mu \mathrm{L}$ of distilled water. PE, naringin, citric acid and gallic acid samples were prepared at $1 \mathrm{mg} \mathrm{mL}{ }^{-1}$. The radical scavenging capacity of the extracts was expressed as the DPPH percentage of inhibition using the same equation as used for the lipid oxidation inhibition assay.

$\mathrm{Fe}^{2+}$ chelating assay: The chelating activity of samples on $\mathrm{Fe}^{2+}$ was measured according to Heimler et al. (2007) PE $(100 \mu \mathrm{L})$ of plant extracts or standards $(1 \mathrm{mg}$ $\mathrm{mL}^{-1}$ ) were diluted up to $1.5 \mathrm{~mL}$ with $0.25 \mathrm{M}$ acetate buffer (pH 4.75) and $25 \mu \mathrm{L}$ of $2 \mathrm{mM} \mathrm{FeCl}_{2}$ and $1 \mathrm{~mL}$ of the same solvent in which plant extracts or standards were dissolved, were added. The solution was incubated at room temperature for $20 \mathrm{~min}$. After incubation, 100 $\mu \mathrm{L}$ of $5 \mathrm{mM}$ ferrozine was added, the mixture was shaken and the absorbance was measured after $5 \mathrm{~min}$ at
$562 \mathrm{~nm}$; the same mixture but without the sample was used as blank. The ability of chelating ferrous ions was calculated according to Equation (3):

Chelating activity $\%=\left[\left(\mathrm{A}_{0}-\mathrm{A}_{\mathrm{s}}\right) / \mathrm{A}_{0}\right] \times 100$

where, $A_{0}$ is the absorbance of the blank and $A_{s}$ is the absorbance of the sample.

\subsection{Film Forming Capacity Assay}

The film forming capacity of pectic extracts was evaluated by preparation of thin films formed by evaporation of the casting solution. Crude pectic extracts $(30 \mathrm{~mL})$ were homogenized with $0.5,1.0$ or $1.5 \%$ glycerol and then were casted in a $150 \mathrm{~mm}$ Petri dish to let dry at $45^{\circ} \mathrm{C}$ for $24 \mathrm{~h}$. The obtained films were peeled from the Petri dishes and stored at $20^{\circ} \mathrm{C}$ in a desiccator $(50 \% \mathrm{RH})$. The dried films were visually inspected for appearance, homogeneity and integrity.

\subsection{Statistical Analyses}

All determinations were carried out in quintuplicate. Results are expressed as mean values \pm standard deviation. Data were statistically analyzed using an ANOVA with a $95 \%$ of confidence. Data analysis was carried out using Minitab Statistical Software Version 16 (Minitab Inc., State College, PA, USA).

\section{RESULTS AND DISCUSSION}

\subsection{Mexican Lime Bagasse and Pomace Composition}

Proximate composition of Mexican lime bagasse and pomace showed that there were significant differences among the two raw materials. The term "pomace" is applied to citrus peel which has been carefully dried after leaching with water at $50-60^{\circ} \mathrm{C}$ to lower the concentration of soluble sugars and acids (May, 1990; El-Nawawi and Heikal, 1996). As observed in Table 1, the composition of Mexican lime bagasse and pomace show significant differences on the different components analyzed; in most of the components, pomace has the lower values and lipid content is almost half of what is found in bagasse.

Approximately $20-30 \%$ of the total dry peel solids must be removed after leaching in order to produce the light-coloured pomace (Braddock and Crandall, 1978), therefore and due to the washing process, a reduction of soluble solids such as sugars, minerals, protein denaturalization (inactive enzyme) and lipid extraction may occur (El-Nawawi, 1995). El-Nawawi and Heikal 
(1996) analyzed the properties of the leached liquid from orange pomace and found soluble solids such sugars, essential oil, flavonoids, denatured proteins and organic acids. Based on these reports, it is suggests that Mexican lime pomace probably contains more extractable pectin than bagasse. The flavedo (coloured-portion) of citrus fruits contains a considerable proportion of oil, which is usually removed by a physical method before the original shape of the citrus fruit is destroyed or after the juice has been extracted. Most methods cause oil cells to burst in a gentle manner to prevent absorption of the oil by the albedo (spongy and uncoloured-portion). The oil is washed off, usually with an excess of water and the oil is usually recovered by centrifugation before juice processing (May, 1990).

\subsection{Physicochemical Characterization of Pectic Extracts (PE)}

A total of $2 \mathrm{~L}$ of pectic extract was obtained for each raw material (bagasse or pomace) and each extraction method (conventional or microwave) and this extract was used to determine total sugar and uronic acid concentration, degree of esterification and pectin yield. Results are shown in Table 2.

Bagasse Microwave extract (BM) and Bagasse Conventional extract (BC) were not significantly different in total sugar content. However, both pomace extracts (PM and PC) were significantly different in total sugar, uronic acids and pectin yield. Pomace Microwave extract (PM) contained the highest total sugars and the highest uronic acids content, as well as the highest pectin yield (Table 2). Microwave radiation liberates the cell wall matrix (Kratchanova et al., 2004) and thereby the peel tissues are rapidly and extensively opened by the microwave treatment. This lead to an increased interaction between extracting solution and raw material in the extraction process; therefore, it leads to an effective increase in pectic extraction yield (Bagherian et al., 2011). As such, pectin yield of PM extract was twice the one obtained from BM extract. Due to the solids removed from lime bagasse in the production of lime pomace, the content of pectin increased and has an impact in pectin yield from this material.
According to the statistical analysis, the degree of esterification was not related to the extraction method or the raw material used, since all results were on the range of 65 to $73 \%$ degree of esterification. With this result, the pectin extracted is considered as a material with a high degree of esterification and is similar to the results reported by Fishman et al. (2006) who found pectin from several lime parts (albedo, flavedo and pulp) with values of DE from 59 to $75 \%$. In our work, bagasse raw material consisted of flavedo, albedo and pulp including seeds.

On the other hand, total phenolic content, expressed as gallic acid equivalents is shown in Table 2. The concentration of phenolic compounds was significantly different among the four treatments. Bagasse microwave extract showed the highest total polyphenol concentration $\left(41.43 \pm 0.04 \mathrm{mg} \mathrm{g}^{-1}\right.$ extract [gallic acid equivalents dry basis]) followed by bagasse conventional extract $\left(37.67 \pm 0.05 \mathrm{mg} \mathrm{g}^{-1}\right.$ extract [gallic acid equivalents dry basis]). The lowest total phenolic content was in pomace conventional extract $\left(34.00 \pm 0.02 \mathrm{mg} \mathrm{g}^{-1}\right.$ raw material [gallic acid equivalents dry basis]). Wang et al. (2007) analyzed eight different citrus fruits and found total polyphonic contents that ranged from $37.3 \pm 1.5$ to $75.9 \pm 3.8 \mathrm{mg} \mathrm{g}^{-1}$ (Gallic acid equivalents dry basis), the highest value was from the edible portion of lemon $(C$. limon). Guimaraes et al. (2010) found $124.63 \pm 0.52$ in lime (C. aurantifolia) peels. In our study, the total polyphenol was in the range of results reported by Wang et al. (2007), but values were lower than those reported by Guimaraes et al. (2010). These differences are mainly due to the specific method used by the authors, to recover the polyphenolic fraction.

Table 1. Mexican lime Bagasse and pomace proximal

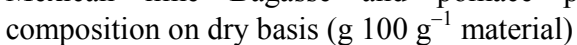

\begin{tabular}{lcc}
\hline Composition & Bagasse $^{\mathrm{a}}$ & Pomace $^{\mathrm{b}}$ \\
\hline Ash & $0.30 \pm 0.00$ & $0.20 \pm 0.00$ \\
Protein & $7.20 \pm 0.04$ & $4.30 \pm 0.02$ \\
Lipid & $1.10 \pm 0.02$ & $0.50 \pm 0.01$ \\
Crude fiber & $15.6 \pm 1.50$ & $24.1 \pm 1.00$ \\
Carbohydrate & $75.8 \pm 2.11$ & $70.9 \pm 1.13$ \\
\hline Values followed by different lower-case & letters are \\
significantly different at $\mathrm{p}<0.05$ &
\end{tabular}

Table 2. Pectic extracts characterization

\begin{tabular}{|c|c|c|c|c|c|}
\hline PE & $\begin{array}{l}\text { Total sugars } \\
\left(\mathrm{mg} \mathrm{g}^{-1} \text { extract) }\right.\end{array}$ & $\begin{array}{l}\text { Uronic acids } \\
\left(\mathrm{mg} \mathrm{g}^{-1} \text { extract }\right)\end{array}$ & $\begin{array}{l}\text { Degree of esterification } \\
(\%)\end{array}$ & $\begin{array}{l}\text { Pectin Yield } \\
\left(\mathrm{g} 100 \mathrm{~g}^{-1}\right)\end{array}$ & $\begin{array}{l}\text { Total phenolic* } \\
\text { ( } \mathrm{mg} \mathrm{g}^{-1} \text { extract) }\end{array}$ \\
\hline$\overline{\mathrm{PM}}$ & $290.06 \pm 9.06^{\mathrm{a}}$ & $314.53 \pm 0.74^{\mathrm{a}}$ & $69.11 \pm 2.38^{\mathrm{a}}$ & $16.9 \pm 0.03^{\mathrm{a}}$ & $38.00 \pm 0.02^{a}$ \\
\hline $\mathrm{PC}$ & $234.94 \pm 4.56^{\mathrm{b}}$ & $230.84 \pm 38.70^{b}$ & $72.79 \pm 2.70^{\mathrm{a}}$ & $15.1 \pm 0.02^{b}$ & $34.00 \pm 0.04^{\mathrm{b}}$ \\
\hline $\mathrm{BM}$ & $207.79 \pm 3.86^{c}$ & $91.37 \pm 21.59^{c}$ & $65.46 \pm 5.35^{\mathrm{a}}$ & $8.40 \pm 0.02^{\mathrm{c}}$ & $41.43 \pm 0.08^{c}$ \\
\hline $\mathrm{BC}$ & $209.30 \pm 2.21^{\mathrm{c}}$ & $131.37 \pm 6.70^{\mathrm{d}}$ & $68.44 \pm 3.24^{\mathrm{a}}$ & $13.3 \pm 0.03^{\mathrm{d}}$ & $37.67 \pm 0.05^{\mathrm{d}}$ \\
\hline
\end{tabular}


In our study, microwaved PE presented a higher polyphenol content than the PE obtained by the conventional method. Microwave energy can potentiate the bioavailability of free pharmacologically active natural compounds by preventing the binding of polyphenols to the plant matrix, because of the heating process in microwave that allows a homogeneous and instantaneous heating of all material (Robinson et al., 2009). Hayat et al. (2010a) found the highest amounts of total phenolic compounds in mandarin peels using a microwave method. They found that microwave extraction of phenolic compounds, increased by modifying the potency of the process, from $50.37 \pm 0.01 \mathrm{mg} \mathrm{g}^{-1}$ extract (250 Watts) to $58.08 \pm 0.01 \mathrm{mg} \mathrm{g}^{-1}$ extract (500 Watts).

\subsection{Phenolic Compounds Present in Mexican Lime Bagasse and Pomace}

The presence of different flavonoids in raw materials and $\mathrm{PE}$ are shown in Table 3 and the respective flavonoids structures are given in Fig. 1. Only two flavanones were quantified using standards (hesperidin and naringin) for quantification. The presence of other flavonoids included coumaric acid in pomace raw material, catechin, resorcinol and methyl gallate in both raw materials (bagasse and pomace) were identified comparing with spectros obtained previously. A high intensity of pyrogallol signal was found in all PE. Ellagic acid and quercetin were found in both, raw materials as well as in PE. Ellagic acid is reported in literature for citric peels (Wang et al., 2007). Bocco et al. (1998) found only naringin and hesperidin in lime peels and several reports point out that hesperidin is the most abundant flavonoid in citric fruits (Rapisarda et al., 1998). The highest amount of flavonoids occurs in the peel and the main flavonoids glucosides found in citrus peel are naringin (Hayat et al., 2010b) and hesperidin (Londono-Londono et al., 2010). Poore (1934) reported that flavonoids glucosides are not leached from the peel, suggesting that they may be destroyed by the heat and mineral acids used during pectin extraction. However, El-Nawawi (1995) recovered naringin and pectin successively from grapefruit peel in a hot water leach at $88-90^{\circ} \mathrm{C}$ for $5 \mathrm{~min}$. All samples except PM presented a higher naringin as compared to hesperidin; Wang et al. (2007) found naringin, hesperidin and neohesperidin as the main flavanones in eight different citric fruits, being hesperidin the most abundant. They also found quercetin as a flavonol found in high concentration in lemon (C. limon); in our study, we detected a peak corresponding to quercetin which remains in PE after treatment for pectin extraction.

Hesperidin content was higher in PE than Pomace raw material. Some polyphenols as hesperidin can react with other components of the vegetal tissue, interfering with pectin extraction, either by improving or decreasing pectin availability. It is well known that hesperidin can form a stable colloidal suspension with pectin; the specific interaction between those two molecules, it is possible because of the neutral sugars in the hesperidin molecule and in the polyuronide polymer of pectin (Rapisarda et al., 1998; Ben-Shalom and Pinto, 1999). Also, it has been demonstrated that the neutral sugars in pectin are involved in the specific interaction with hesperidin and this interaction can explain that hesperidin is recovered with pectin extraction from pomace (Cerna et al., 2003). There are many variables that can influence the behavior of polyphenols extracted along with pectin, but according to the conditions used, it was suggested that temperature and solvent type were the main factors related to polyphenol content in PE. In the case of microwave-assisted extraction, energy power and microwave application time influences are factors that affect the release of phenolic compounds from the raw material. Several studies has demonstrated that higher levels of these two factors can lead to degradation of flavonols, including naringin (Cerna et al., 2003; Fishman et al., 2006; Hayat et al., 2010a).

Table 3. Phenolic presence in raw materials and pectic extracts

\begin{tabular}{lllllll}
\hline Component & Pomace & Bagasse & PM & PC & BM & BC \\
\hline Naringin & $2.56 \mathrm{mAU}$ & $102.8 \mathrm{mAU}$ & $2.27 \mathrm{mAU}$ & $6.94 \mathrm{mAU}$ & $10.70 \mathrm{mAU}$ & $9.40 \mathrm{mAU}$ \\
Hesperidin & $1.92 \mathrm{mAU}$ & $55.2 \mathrm{mAU}$ & $7.12 \mathrm{mAU}$ & $6.77 \mathrm{mAU}$ & $8.19 \mathrm{mAU}$ & $8.01 \mathrm{mAU}$ \\
Coumaric acid & $*$ & ND & ND & ND & ND & ND \\
Catechin & $*$ & $*$ & ND & ND & ND & ND \\
Pyrogallol & $*$ & $*$ & $* *$ & ND & ND & ND \\
Resorcinol & $*$ & $*$ & ND & ND & ND & $*$ \\
Methyl gallate & $*$ & $*$ & $*$ & $*$ & $*$ & $*$ \\
Quercetin & $*$ & $*$ & $*$ & $*$ & & \\
Ellagic acid & $*$ & $*$ & & $*$ & &
\end{tabular}

ND Not detected; * Presence; ** High intensity

$\mathrm{PM}=$ Pomace microwave extract; $\mathrm{PC}=$ Pomace conventional extract; $\mathrm{BM}=$ Bagasse microwave extract; $\mathrm{BC}=$ Bagasse conventional extrac 


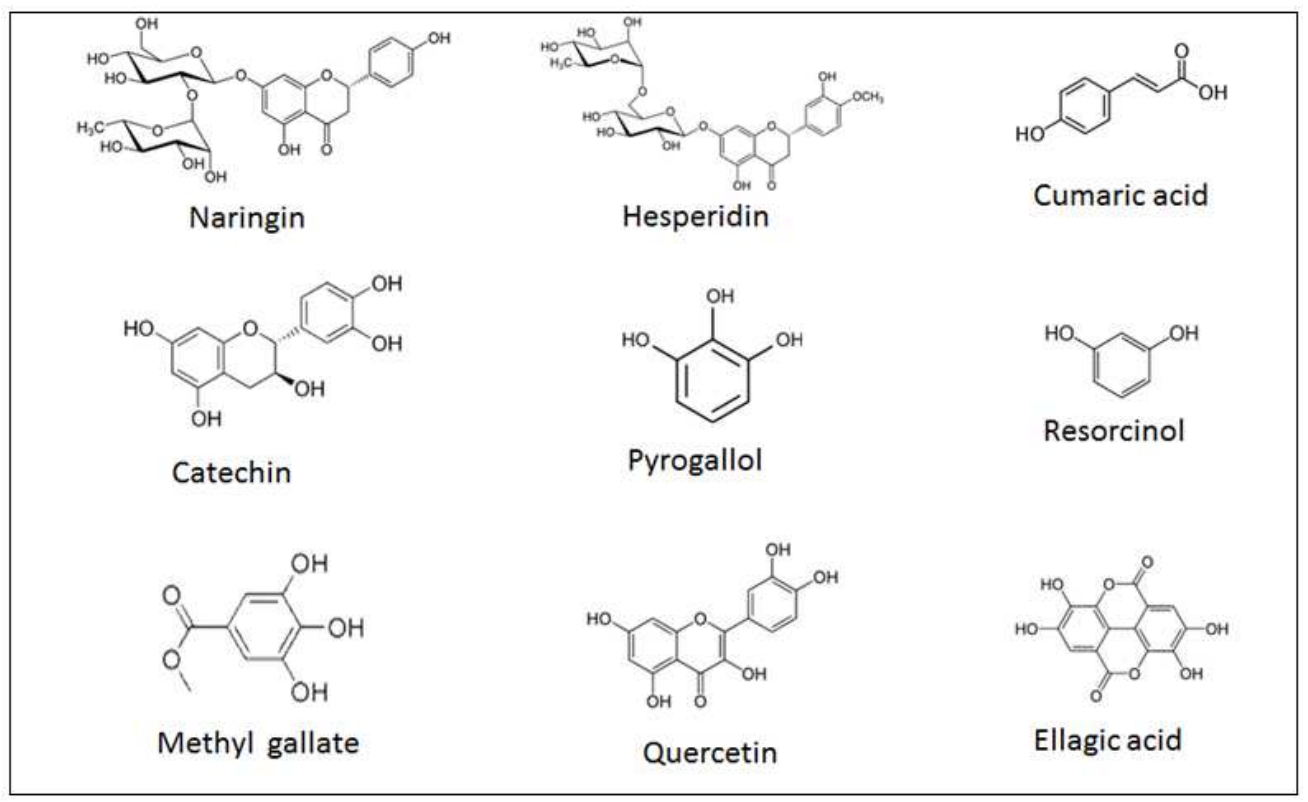

Fig. 1. Structures of flavonoids identified in pectic extracts from Mexican lime bagasse and pomace

\subsection{Molecular Weight and Composition of the Polymers Present in the Pectic Extracts}

In order to confirm the identity of the pectin from the extracts of Mexican lime, PE polysaccharides were analyzed by FT-IR and their spectra were compared against polygalacturonic acid and commercial pectin used as standard (Fig. 2). It was found that the FT-IR spectra of PE exhibited similarities on the absorption patterns to those of commercial pectin standards; therefore, it is confirmed that the polysaccharide extracted from Mexican lime bagasse and pomace is pectin. FT-IR spectra at wavelength between 950 and $1200 \mathrm{~cm}^{-1}$ are considered as the portion of the 'fingerprint' region for carbohydrates (Kalapathy and Proctor, 2001; Cerna et al., 2003).

Analysis of the FT-IR spectra revealed that the broader band of absorption between 3600 and $2500 \mathrm{~cm}^{-1}$ was due to $\mathrm{O}-\mathrm{H}$ stretching whereas strong absorbance observed at $1730-1760$ and $1600-1630 \mathrm{~cm}^{-1}$ were attributed to the ester carbonyl $(\mathrm{CaO})$ groups and carboxyl ion stretching band $\left(\mathrm{COO}^{-}\right)$, respectively (Kamnev et al., 1998). In order to determine whether Mexican lime bagasse and pomace pectin is a low or high methoxy pectin, the FT-IR spectra of PE were compared against to commercial citrus pectin with $70 \%$ degree of esterification. The intensity of the absorbance of the ester carbonyl groups (1730-1760 $\mathrm{cm}^{-1}$ ) increased as the degree of esterification was higher; in contrast, the intensity of the free carboxyl stretching band decreased (Manrique and Lajolo, 2002). The qualitative comparison of absorbencies at the two characteristic peaks of pectin from Mexican lime bagasse and pomace suggest that is a high- methoxyl pectin. Quantitative determination degree of esterification of Mexican lime bagasse and pomace PE is also reported (Table 4).

A relation between the integration of areas under the curve at two different wavelengths can be used to confirm if pectin found in the extracts is highmethoxyl pectin (Dorman et al., 2004), as described in the following formula:

$$
\mathrm{DE}=\mathrm{A}_{1730} /\left(\mathrm{A}_{1730}+\mathrm{A}_{1600}\right) \times 100
$$

where, $A_{1730}$ is area under the curve at $1730 \mathrm{~cm}^{-1}$ signal and $\mathrm{A}_{1600 \text { si }}$ area under the curve at $1600 \mathrm{~cm}^{-1}$ signal.

The qualitative comparison of the absorbance in both peaks characteristic confirms the degree of esterification detected chemically above and suggests the existence of high methoxyl pectins in PE.

Another important parameter in the description of pectin obtained from the Mexican lime bagasse and pomace, is the molecular weight of the pectin polymer and the distribution of the pectin compounds present, as determined by gel filtration chromatography (Fig. 3). Microwave pectic extracts (PM and $\mathrm{BM}$ ) presented their higher peaks around fraction 26 to 28 corresponding to retention time of 104 min. Conventional PE (PC and $\mathrm{BC}$ ) presented higher peaks around fraction 18 to 20 (72 $\mathrm{min})$. This results indicates that PE obtained by conventional methods have a molecular weights close to $670 \mathrm{kDa}$ and $\mathrm{PE}$ extracted with microwave technology, presented a depolymerization so that the most abundant component had a molecular weight of $12 \mathrm{kDa}$. This results also indicate that pomace extracts had higher pectin yields than bagasse extracts. 


\subsection{Antioxidant Activity}

Citrus fruits are known for their rich sources of bioactive compounds, including organic acids, vitamin $\mathrm{C}$, phenolic compounds and flavonoids, with potential health-promoting properties (Bocco et al., 1998; Kawaii et al., 1999; Manthey and Grohmann, 2001; Yapo et al., 2007; Wang et al., 2007; GonzalezMolina et al., 2010; Hayat et al., 2010b; LondonoLondono et al., 2010). The interaction of those compounds contributes to the overall antioxidant activity and it is difficult to measure total antioxidant activity on the basis of individual components
(Yapo et al., 2007). Therefore, the antioxidant activity expressed in this study was in the form of total activity. Although numerous techniques are available to evaluate antioxidant activity, there is no single procedure capable of integrating the full set of mechanisms typical of an antioxidant (Frankel and Meyer, 2000; Lee et al., 2003). Three methods, DPPH scavenging, lipid oxidation inhibition and $\mathrm{Fe}^{2+}$ chelating activity, based on different principles were selected for measurement of antioxidant activity of pectic extracts. Results from antioxidant activity are shown in Fig. 4 as percentage of inhibition or chelating activity.

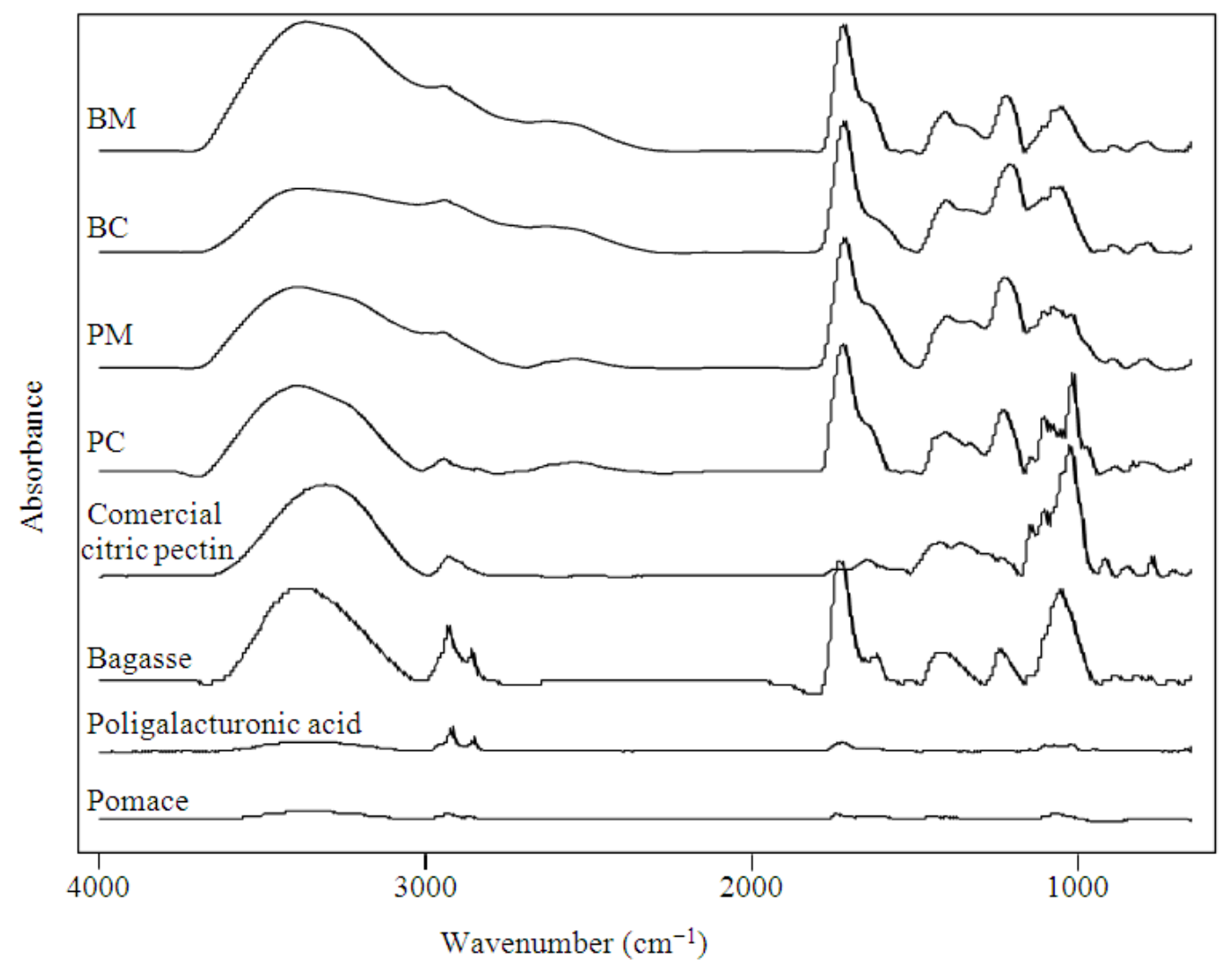

Fig. 2. FTIR/ATR spectrums for pectic extracts and raw materials from Mexican lime bagasse and pomace

Table 4. Degree of esterification estimation of PE by FT-IR measurements

\begin{tabular}{lclll}
\hline PE & $\begin{array}{l}\mathrm{A}_{1730 \mathrm{~cm}-1} \\
(\mathrm{mAU})\end{array}$ & $\begin{array}{l}\mathrm{A}_{1730-1600 \mathrm{~cm}-1} \\
(\mathrm{mAU})\end{array}$ & $\begin{array}{l}\mathrm{DE}^{*} \\
(\%)\end{array}$ & $\begin{array}{l}\mathrm{DE}^{* *} \\
(\%)\end{array}$ \\
\hline PM & 92.33 & 132.70 & $69.58 \pm 0.95^{\mathrm{a}}$ & $69.11 \pm 2.38$ \\
$\mathrm{a}$ & 62.61 & 90.62 & $69.09 \pm 0.49^{\mathrm{a}}$ & $72.79 \pm 2.70$ \\
$\mathrm{a}$ & 107.24 & 174.51 & $61.45 \pm 0.38^{\mathrm{b}}$ & $65.46 \pm 5.35$ \\
$\begin{array}{l}\mathrm{B} \\
\mathrm{a}\end{array}$ & 161.23 & 230.35 & $69.99 \pm 1.01^{\mathrm{a}}$ & $68.44 \pm 3.24$ \\
$\begin{array}{l}\mathrm{BC} \\
\mathrm{a}\end{array}$ & & &
\end{tabular}

\footnotetext{
* IR method esterification of degree; ** Titration method esterification of degree; A Area under a curve
} 


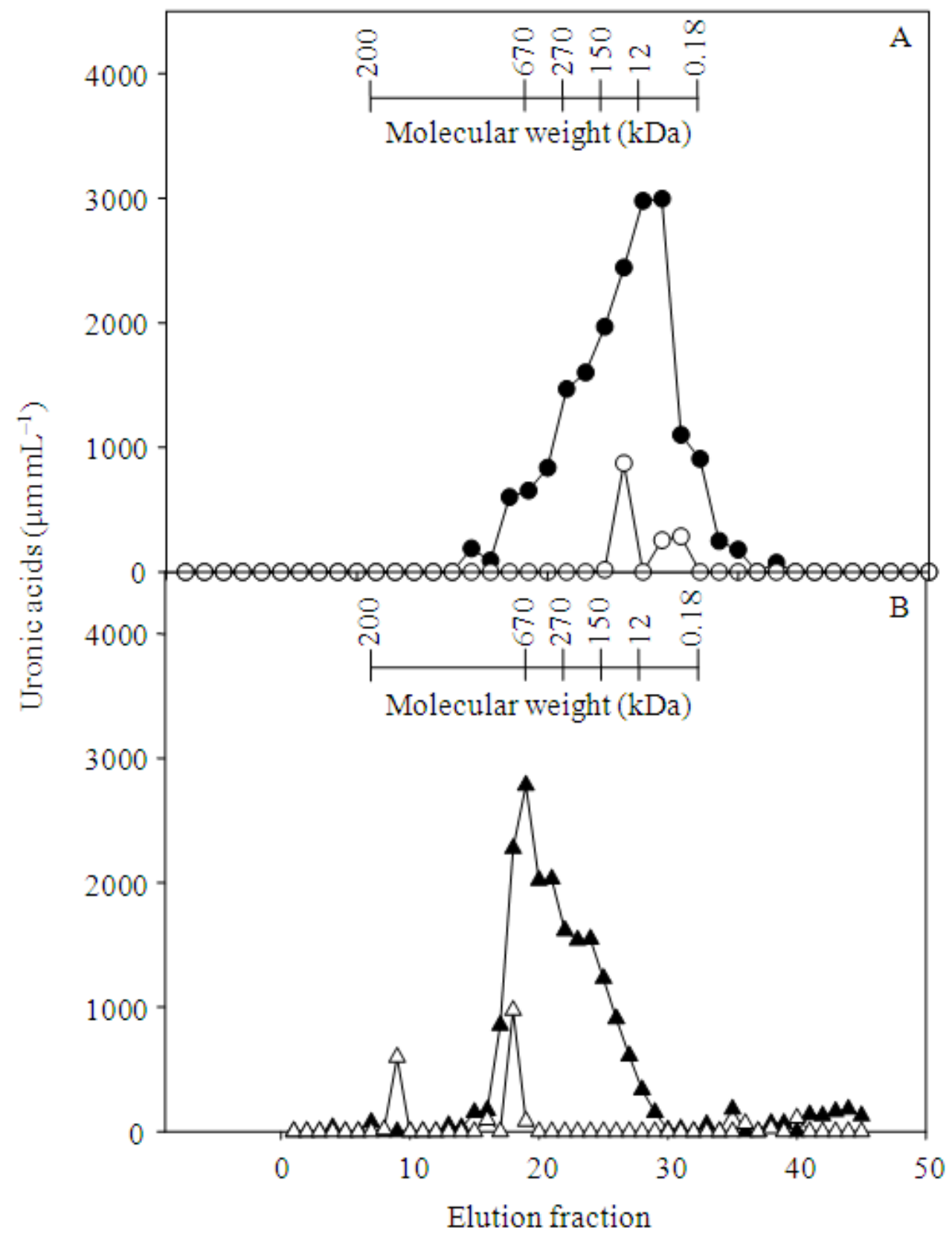

Fig. 3. Gel filtration profiles of pectic extracts from Mexican lime pomace and bagasse. Black circles, PM; Open circles, BM; Black triangles, $\mathrm{PC}$; Open triangles, $\mathrm{BC}$

Gallic acid standard showed excellent activity on all three antioxidant assays ( $>95 \%)$. Free radical scavenging is one of the most studied and reported mechanism of inhibition of lipid oxidation; The DPPH (1, 1,-diphenyl-2-picryl hydrazine) free radical scavenging assay is a rapid method and one of the commonly reported to characterize antioxidant activity of plant material (Lee et al., 2003). In this study, pectic extracts showed weak antioxidant activities in the DPPH assay $(<10 \%)$ at $30 \mathrm{~min}$ reaction. Flavanones, such as naringin, due to the lack of conjugation provided by the 2,3-double bond with the 4-oxo group, are weak antioxidants (Zhou et al., 2006). This is consistent with the results of this study were it was found that naringin standard presented less than $40 \%$ of DPPH scavenging activity. 


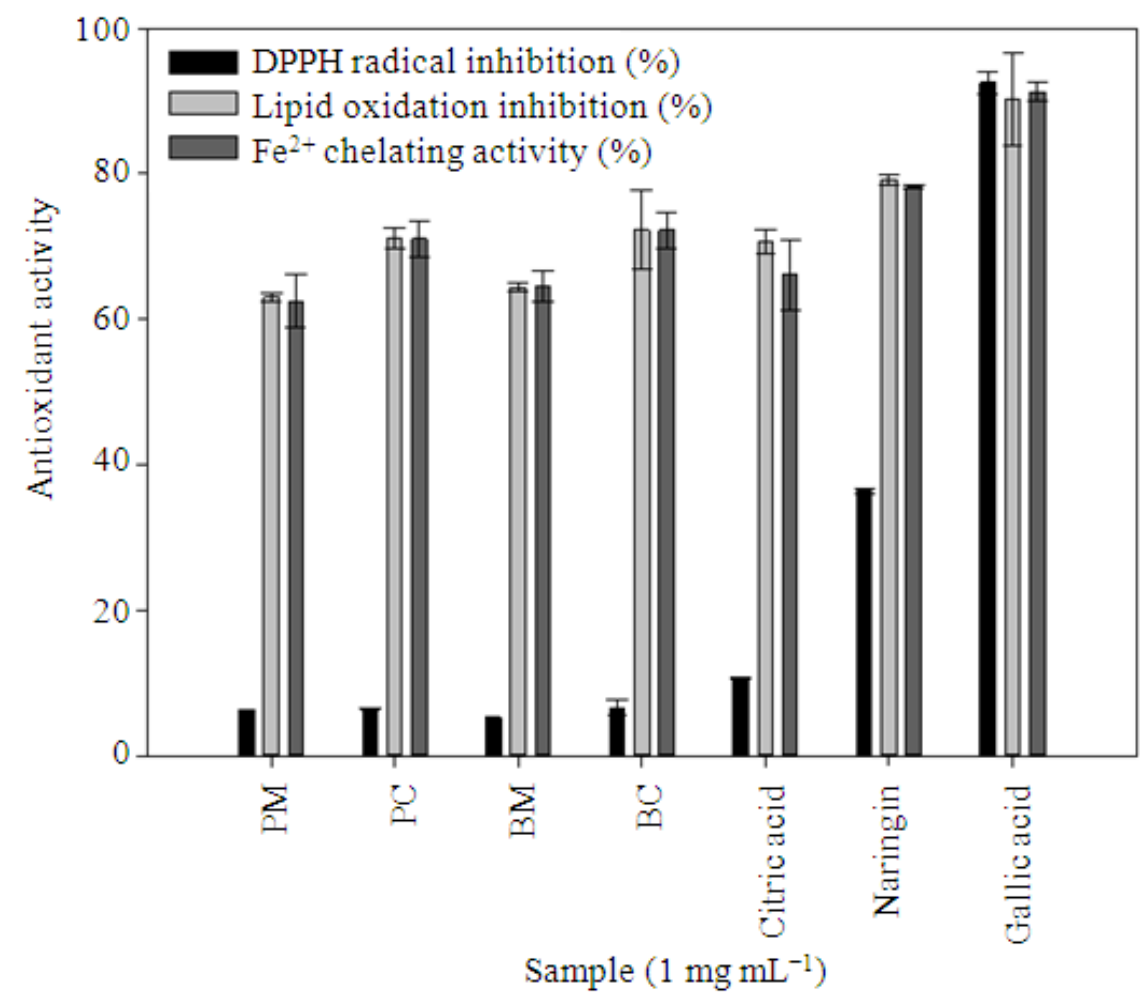

Fig. 4. Antioxidant activity comparisons of the four pectic extracts from Mexican lime pomace and bagasse. Citric acid, naringin and gallic acid are used as standards

All four pectic extracts presented similar antioxidant activities in lipid oxidation inhibition and $\mathrm{Fe}^{2+}$ chelating activity. Conventional pectic extracts (PC and $\mathrm{BC}$ ) had better antioxidant inhibition than microwave pectic extracts (PM and BM), however, lipid oxidation and $\mathrm{Fe}^{2+}$ chelating activity did not have statistically significant differences among them; all the extracts had similar antioxidant activity as the naringin standard. The results of antioxidant activity by the three methods used, suggests that antioxidant components present in each of the four pectic extracts, could possess different mechanism of action to inhibit lipid oxidation.

The assay of inhibition of lipid oxidation simulates the oxidation of lipids in foods (Huang et al., 2005). It can be observed that the pectic extracts obtained by conventional extraction are capable of inhibiting linoleic acid oxidation with an effectiveness of $71.22 \pm 1.01$ and $72.28 \pm 1.27 \%$ of inhibition (PC and $\mathrm{BC}$, respectively). For the microwave PE lipid oxidation inhibition was lower $(63.07 \pm 0.98 \%$ for $\mathrm{PM}$ and $64.37 \pm 1.29 \%$ for BM). Also, conventional pectic extracts bound $\geq 70 \%$ of $\mathrm{Fe}^{2+}$ and Microwave pectic extracts only $\geq 60 \%$. Many studies on chelation of iron ions by isolated phenolic acids, flavonoids and anthocyanins, have established that suitably oriented functional groups in the structure of the ligand are essential for the formation of the metal ionphenolic compound complexes (Brown and Kelly,
2007). Phenolic compounds with a single $\mathrm{OH}$ group on the aromatic ring do not bind iron ions, as in the catechol group (as quercitin and hesperidin) or the galloyl group (trihydroxyphenyl) as in methyl gallate and pyrogallol (Zhou et al., 2006). Moreover, it is well known that pectin substances (soluble, insoluble fibers and modified pectin) bind through hydroxyl groups of uronic acids. Modified citrus pectin, alone or alginate combinations was used to decrease body heavy metal burden in patients Also, modified pectin has been used to decrease lead in children's blood serum levels. In this sense, $\mathrm{Fe}^{2+}$ chelating activity could be due a synergic effect between the phenolic compounds and the uronic acids presence of PE.

\subsection{Film Forming Capacity Assay}

Films obtained by using PE from microwaveassisted method (BM and PM) in the casting solution, had undesirable characteristics; with 0.5 and $1.0 \%$ glycerol were very brittle films and with $1.5 \%$ glycerol were very elastic and difficult to handle. On the other hand, films made from conventional method were easy to peeled off and handle (Fig. 5), presented good appearance, homogeneity and integrity. Microwave assisted PE, which have a lower molecular weight than the one obtained by conventional methods, was not able to form a matrix solution, appropriate for a latter film formation. 


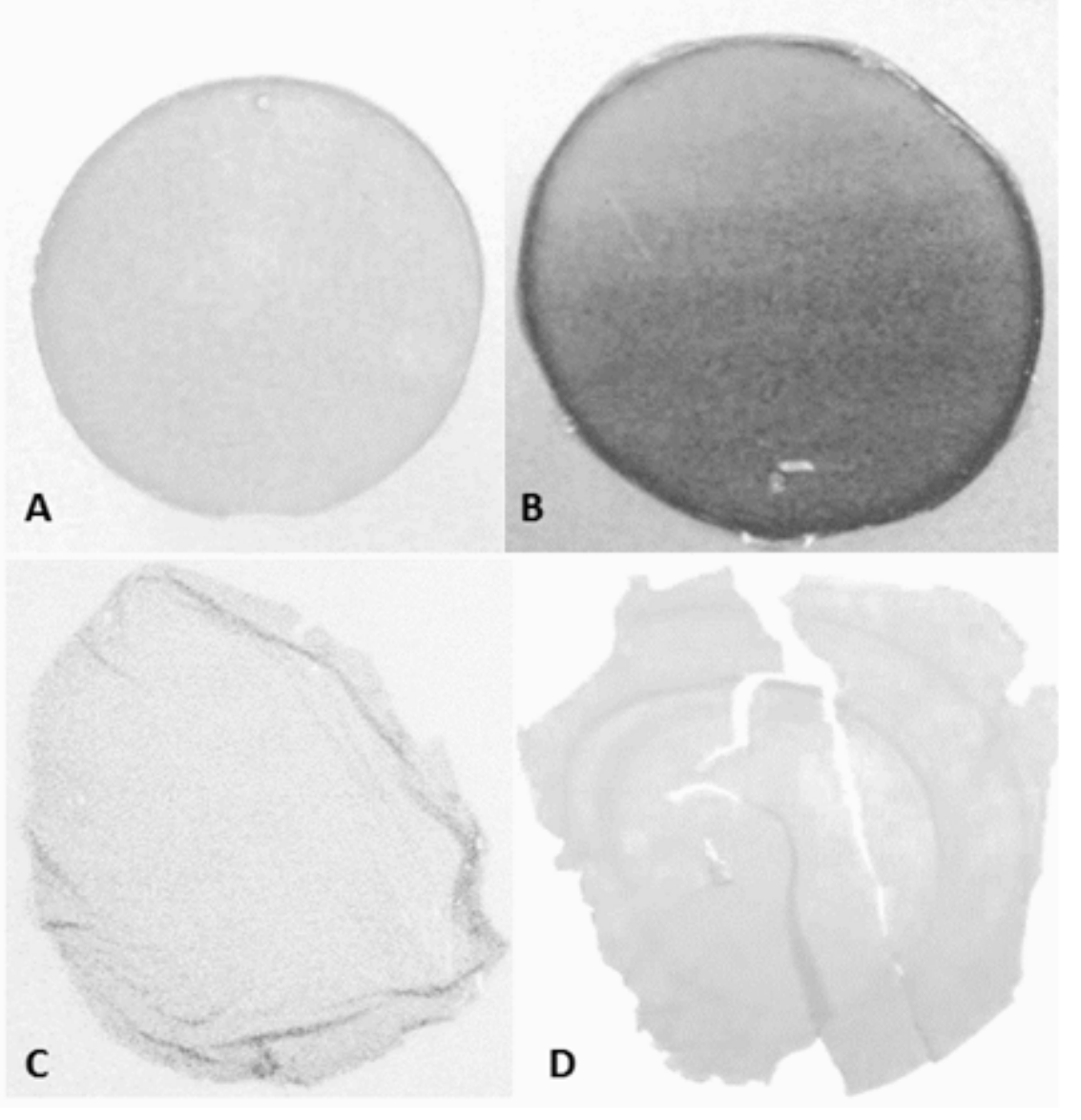

Fig. 5. Pectic extracts Film appearance. (A) PC $1.0 \%$ glycerol, (B) BC $1.0 \%$ glycerol, (C) PM $1.0 \%$ glycerol and (D) BM $1.0 \%$ glycerol

\section{CONCLUSION}

Conventional and microwave methods were used to obtain pectic extracts from two raw materials: pomace and bagasse from Mexican lime. The yield of pectin from pomace was greater than that from bagasse. The extraction method showed to have an impact on the molecular weight and polymerization of pectin compound. The polyphenols of the four pectic extracts from Mexican lime bagasse and pomace were also examined; pomace extracts showed the highest pectin yield and the lower polyphenolic content including naringin and hesperidin. Mexican lime Bagasse pectic extracts here presented, can have potential as raw material to form edible films and coatings.

\section{ACKNOWLEDGEMENT}

Researcher D Sanchez-Aldana thanks the Mexican Council for Science and Technology (CONACYT) for the graduate scholarship.

\section{REFERENCES}

Ahmad, M.M., Z. Iqbal, F.M. Anjum and J.I. Sultan, 2006. Genetic variability to essential oil composition in four citrus fruit species. Pak. J. Botany, 38: 319-324.

Assifaoui, A., C. Loupiac, O. Chambin and P. Cayot, 2010. Structure of calcium and zinc pectinate films investigated by FTIR spectroscopy. Carbohydrate Res., 345: 929-933. DOI: 10.1016/j.carres.2010.02.015

Bagherian, H., F. Zokaee A.F. Ashtiani and M. Mohtashamy, 2011. Comparisons between conventional, microwave-and ultrasound-assisted methods for extraction of pectin from grapefruit. Chemical Eng. Process. Process Intensificat., 50: 1237-1243. DOI: 10.1016/j.cep.2011.08.002

Ben-Shalom, N. and R. Pinto, 1999. Natural colloidal particles: The mechanism of the specific interaction between hesperidin and pectin. Carbohydrate Polymers, 38: 179-182. DOI: 10.1016/S01448617(98)00111-8 
Blumenkrantz, N. and G. Asboe-Hansen, 1973. New method for quantitative determination of uronic acids. Analytical Biochem., 54: 484-489. DOI: 10.1016/0003-2697(73)90377-1

Bocco, A., M.E. Cuvelier, H. Richard and C. Berset, 1998. Antioxidant activity and phenolic composition of citrus peel and seed extracts. J. Agric. Food Chem., 46: 2123-2129. DOI: $10.1021 /$ jf9709562

Bochek, A.M., N.M. Zabivalova and G.A. Petropavlovskii, 2001. Determination of the esterification degree of polygalacturonic acid. Russian J. Applied Chem., 74: 796-799. DOI: 10.1023/A:1012701219447

Braddock, R.J. and P.G. Crandall, 1978. Properties and recovery of waste liquids from citrus pectin pomace manufacture. J. Food Sci., 43: 1678-1679. DOI: 10.1111/j.1365-2621.1978.tb07386.x

Brown, J.E. and M.F. Kelly, 2007. Inhibition of lipid peroxidation by anthocyanins, anthocyanidins and their phenolic degradation products. European J. Lipid Sci. Technol., 109: 66-71. DOI: 10.1002/ejlt.200600166

Cerna, M., A.S. Barros, A. Nunes, S.M. Rocha and I. Delgadillo et al., 2003. Use of FT-IR spectroscopy as a tool for the analysis of polysaccharide food additives. Carbohydrate Polymers, 51: 383-389. DOI: 10.1016/S01448617(02)00259-X

Coma, V., 2010. Polysaccharide-based biomaterials with antimicrobial and antioxidant Properties. Polimeros, 20: 1-12. DOI: 10.4322 /polimeros020ov002

Dorman, H.D., O. Bachmayer, M. Kosar and R. Hiltunen, 2004. Antioxidant properties of aqueous extracts from selected Lamiaceae species grown in Turkey. J. Agric. Food Chem., 52: 762-770. DOI: $10.1021 / \mathrm{jf034908v}$

Dubois, M., K.A. Gilles, J.K. Hamilton, P.T. Rebers and F. Smith, 1956. Colorimetric method for determination of sugars and related substances. Anal. Chem., 28: 350-356. DOI: 10.1021/ac60111a017

El-Nawawi, S.A. and Y.A. Heikal, 1996. Production of pectin pomace and recovery of leach liquids from orange peel. J. Food Eng., 28: 341-347. DOI: 10.1016/0260-8774(95)00033-X

El-Nawawi, S.A., 1995. Extraction of citrus glucosides. Carbohydrate Polymers, 27: 1-4. DOI: 10.1016/0144-8617(95)00036-7

Fishman, M.L., D.R. Coffin, C.I. Onwulata and R.P. Konstance, 2004. Extrusion of pectin and glycerol with various combinations of orange albedo and starch. Carbohydrate Polymers, 57: 401-413. DOI: $10.1016 /$ j.carbpol.2004.05.014
Fishman, M.L., H.K. Chau, P.D. Hoagland and A.T. Hotchkiss, 2006. Microwave-assisted extraction of lime pectin. Food Hydrocolloids, 20: 1170-1177. DOI: 10.1016/j.foodhyd.2006.01.002

Frankel, E.N. and A.S. Meyer, 2000. The problems of using one-dimensional methods to evaluate multifunctional food and biological antioxidants. J. Sci. Food Agric., 80: 1925-1941. DOI: 10.1002/1097-0010(200010)80:13<19

Gee, M., R.M. Reeve and R.M. McCready, 1959. Measurement of plant pectic substances, reaction of hydroxylamine with pectinic acids: Chemical studies and histochemical estimation of the degree of esterification of pectic substances in fruit. J. Agric. Food Chem., 7: 34-38. DOI: 10.1021/jf60095a005

Gonzalez-Molina, E., R. Dominguez-Perles, D.A. Moreno and C. Garcia-Viguera, 2010. Natural bioactive compounds of Citrus limon for food and health. J. Pharmaceutical Biomed. Anal., 51: $327-$ 345. DOI: 10.1016/j.jpba.2009.07.027

Guimaraes, R., L. Barros, J. Barreira, M.J. Sousa and A.M. Carvalho et al., 2010. Targeting excessive free radicals with peels and juices of citrus fruits: grapefruit, lemon, lime and orange. Food Chemical Toxicol., 48: 99-106. DOI: 10.1016/j.fct.2009.09.022

Hayat, K., X. Zhang, H. Chen, S. Xia and C. Jia et al., 2010b. Liberation and separation of phenolic compounds from citrus mandarin peels by microwave heating and its effect on antioxidant activity. Separat. Purificat. Technol., 73: 371-376. DOI: 10.1016/j.seppur.2010.04.026

Hayat, K., X. Zhang, U. Farooq, S. Abbas and S. Xia et al., 2010a. Effect of microwave treatment on phenolic content and antioxidant activity of citrus mandarin pomace. Food Chem., 123: 423-429. DOI: 10.1016/j.foodchem.2010.04.060

Heimler, D., L. Isolani, P. Vignolini, S. Tombelli and A. Romani, 2007. Polyphenol content and antioxidative activity in some species of freshly consumed salads. J. Agric. Food Chem., 55: 1724-1729. DOI: 10.1021/jf0628983

Huang, D., B. Ou and R.L. Prior, 2005. The chemistry behind antioxidant capacity assays. J. Agric. Food Chem., 53: 1841-1856. DOI: 10.1021/jf030723c

Kalapathy, U. and A. Proctor, 2001. Effect of acid extraction and alcohol precipitation conditions on the yield and purity of soy hull pectin. Food Chem., 73: 393-396. DOI: 10.1016/S03088146(00)00307-1

Kamnev, A.A., M. Colina, J. Rodriguez, N.M. Ptitchkina and V.V Ignatov, 1998. Comparative spectroscopic characterization of different pectins and their sources. Food Hydrocolloids, 12: 263-271. DOI: 10.1016/S0268-005X(98)00014-9 
Kawaii, S., Y. Tomono, E. Katase, K. Ogawa and M. Yano, 1999. Quantitation of flavonoid constituents in citrus fruits. J. Agric. Food Chem., 47: 35653571. DOI: $10.1021 /$ jf990153+

Kratchanova, M., E. Pavlova and I. Panchev, 2004. The effect of microwave heating of fresh orange peels on the fruit tissue and quality of extracted pectin. Carbohydrate Polymers, 56: 181-185. DOI: 10.1016/j.carbpol.2004.01.009

Lee, S.E., H.J. Hwang, J.S. Ha, H.S. Jeong and J.H. Kim, 2003. Screening of medicinal plant extracts for antioxidant activity. Life Sci., 73: 167-179. DOI: 10.1016/S0024-3205(03)00259-5

Li, B.B., B. Smith and M.M Hossain, 2006. Extraction of phenolics from citrus peels I: Solvent extraction method. Separat. Purificat. Technol., 48:182-188. DOI: 10.1016/j.seppur.2005.07.005

Liu, Y., J. Shi and T.A.G. Langrish, 2006. Water-based extraction of pectin from flavedo and albedo of orange peels. Chemical Eng. J., 120: 203-209. DOI: 10.1016/j.cej.2006.02.015

Londono-Londono, J., V.R.D Lima, O. Lara, A. Gil and T.B.C. Pasa et al., 2010. Clean recovery of antioxidant flavonoids from citrus peel: Optimizing an aqueous ultra-sound-assisted extraction method. Food Chem., 119: 81-87. DOI: 10.1016/j.foodchem.2009.05.075

Ma, Y.Q., J.C. Chen, D.H. Liu and X.Q. Ye, 2009. Simultaneous extraction of phenolic compounds of citrus peel extracts: Effect of ultrasound. Ultrason. Sonochem., $\quad 16$ : 57-62. DOI: 10.1016/j.ultsonch.2008.04.012

Maftoonazad, N., H.S. Ramaswamy, M. Moalemiyan and A.C. Kushalappa, 2007. Effect of pectinbased edible emulsion coating on changes in quality of avocado exposed to Lasiodiplodia theobromae infection. Carbohydrate Polymers, 68: 341-349. DOI: 10.1016/j.ultsonch.2008.04.012

Manrique, G.D. and F.M. Lajolo, 2002. FT-IR spectroscopy as a tool for meassuring degree of methyl esterification in pectins isolated from ripening papaya fruit. Postharvest Biol. Technol., 25: 99-107. DOI: 10.1016/S0925-5214(01)00160-0

Manthey, J.A. and K. Grohmann, 2001. Phenols in citrus peel byproducts. Concentrations of hydroxycinnamates and polymethoxylated flavones in citrus peel molasses. J. Agric. Food Chem., 49: 3268-3273. DOI: 10.1021/jf010011r

Masmoudi, M., S. Besbes, M. Chaabouni, C. Robert and M. Paquot et al., 2008. Optimization of pectin extraction from lemon by-product with acidified date juice using response surface methodology. Carbohydrate Polymers, 74: 185-192. DOI: 10.1016/j.carbpol.2008.02.003
May, C.D., 1990. Industrial pectins: Sources, production and applications. Carbohydrate Polymers, 12: 79-99. DOI: 10.1016/0144-8617(90)90105-2

Molyneux, P., 2004. The use of the stable free radical Diphenylpicrylhydrazyl (DPPH) for estimating antioxidant activity. Songklanakarin J. Sci. Technol., 26: 211-219.

Poore, H.D., 1934. Recovery of Naringin and Rectin from Grapefruit Residue. Indus. Eng. Chem., 26: 637-639. DOI: 10.1021/ie50294a011

Rapisarda, P., G. Carollo, B. Fallico, F. Tomaselli and E. Maccarone, 1998. Hydroxycinnamic acids as makers of Italian orange juices. J. Agric. Food Chem., 26: 464-470. DOI: 10.1021/jf9603700

Robinson, J.P., S.W. Kingman, C.E. Snape, H. Shang and R. Barranco et al., 2009. Separation of polyaromatic hydrocarbons from contaminated soils using microwave heating. Separat. Purificat. Technol., 69: 249-254. DOI: 10.1016/j.seppur.2009.07.024

Shrestha, A.K., J. Arcot and J.L. Paterson, 2003. Edible coating materials-their properties and use in the fortification of rice with folic acid. Food Res. Int., 36: 921-928. DOI: 10.1016/S0963-9969(03)00101-7

Singleton, V.L., R. Orthofer and R.M. LamuelaRaventos, 1999. [14] Analysis of total phenols and other oxidation substrates and antioxidants by means of folin-ciocalteu reagent. Methods Enzymol., 299: 152-178. DOI: 10.1016/S0076-6879(99)99017-1

Sothornvit, R. and N. Pitak, 2007. Oxygen permeability and mechanical properties of banana films. Food Res. Int., 40: 365-370. DOI: 10.1016/j.foodres.2006.10.010

Starzynska-Janiszewska, A., B. Stodolak and M. Jamroz, 2008. Antioxidant properties of extracts from fermented and cooked seeds of Polish cultivars of Lathyrus sativus. Food Chem., 109: 285-292. DOI: 10.1016/j.foodchem.2007.12.028

Wang, Y.C., Y.C. Chuang and Y.H. Ku, 2007. Quantitation of bioactive compounds in citrus fruits cultivated in Taiwan. Food Chem., 102: 1163-1171. DOI: 10.1016/j.foodchem.2006.06.057

Yapo, B.M., C. Robert, I. Etienne, B. Wathelet and M. Paquot, 2007. Effect of extraction conditions on the yield, purity and surface properties of sugar beet pulp pectin extracts. Food Chem., 100: 1356-1364. DOI: 10.1016/j.foodchem.2005.12.012

Yeoh, S., J. Shi and T.A.G. Langrish, 2008. Comparisons between different techniques for water-based extraction of pectin from orange peels. Desalination, 218: 229-237. DOI: 10.1016/j.desal.2007.02.018 
Zapata, A.D., C.A. Escobar, S.F. Cavalitto and R.A. Hours, 2009. Evaluación de la capacidad de solubilización de pectina de cascara de limón usando protopectinasa-SE. Vitae, 16: 67-74.
Zhou, K., J.J. Yin and L.L. Yu, 2006. ESR determination of the reactions between selected phenolic acids and free radicals or transition metals. Food Chem., 95: 446-457. DOI: $10.1016 /$ j.foodchem.2005.01.026 